\title{
A IMPORTÂNCIA DA EDUCAÇÃO ESCOLAR EM FLORESTAN FERNANDES: DESAFIOS E PERSPECTIVAS DA DEMOCRATIZAÇÃO
}

\author{
Ana Maria Alves de ALMEIDA ${ }^{1}$ \\ Lucíola Andrade MAIA ${ }^{2}$
}

RESUMO: Entendendo a educação como um direito de todos e que foi conquistado desde a Constituição Federal (1988). Neste sentido, este estudo tem como objetivo central desvelar o percurso histórico da educação brasileira para em seguida, analisar a efetivação do direito à educação compreendendo a dinâmica política em prol de sua garantia. Além de destacar a atuação intelectual e prática de Florestan Fernandes na investida em favor da democratização da educação brasileira. O trabalho foi elaborado a partir da pesquisa bibliográfica e documental, tendo como principais balizadores Candido (2001) Saviani (1996), Ianni (2004). Ademais, tomamos por referência artigos científicos e revistas que terçam sobre o assunto. Nesse ínterim, percebemos que a prática educativa, a produção científica e a militância incansável da ação de Florestan Fernandes permanecem como uma contribuição significativa, servindo de exemplo impulsionador as lutas que somos convocados a travar em prol da democratização e da qualidade da educação.

PALAVRAS- CHAVE: Florestan Fernandes. Educação. Democratização.

\section{Introdução}

A educação é, sem dúvida, algo essencial para o desenvolvimento completo do individuo, ou seja, tanto na parte intelectual quanto da física. E atualmente é tida como o pilar mais importante para o desenvolvimento de uma nação, porque é por meio da produção de conhecimentos que um país cresce, aumentando sua renda e a qualidade de vida das pessoas.

De fato, entende-se que esta segue o percurso natural da vida do ser humano, devendo ser alicerçada nos valores de solidariedade, justiça social e sustentabilidade, cuja finalidade é o pleno desenvolvimento da pessoa humana compromissada com a transformação social.

Segundo Meksenas (2002 apud COUTO; SANTOS, 2009), a educação nasce quando se transmite e se assegura as outras pessoas o conhecimento de crenças, técnicas e hábitos que um grupo social já desenvolveu, a partir de suas experiências de

${ }^{1}$ Graduanda do curso de Serviço Social. UECE - Universidade Estadual do Ceará. Fortaleza - CE - Brasil. 60740-000 - a.alvesdealmeida@yahoo.com.br.

${ }^{2}$ Doutora em Educação Brasileira. UFC - Universidade Federal do Ceará; Professora do Curso de Pedagogia. UECE - Universidade Estadual do Ceará. Fortaleza - CE - Brasil. 60740-000 luciolamaia1313@gmail.com. 
sobrevivência. Neste sentido, pode-se afirmar que o nascimento da educação surge quando o ser humano sente a necessidade de converter as suas práticas cotidianas ao seu semelhante.

Já para Freire (1996) a educação não deve ser uma mera transmissão de conhecimento, mas criar uma possibilidade do educando construir o seu próprio conhecimento baseado com o conhecimento que ele trás de seu dia-a-dia familiar.

Assim, cabe à escola, na sociedade moderna, criar uma comunhão de ideias e sentimentos entre os membros de uma mesma sociedade, através da internalização no indivíduo da tradição cultural dessa sociedade, dos valores do grupo ou dos grupos aos quais o sujeito está integrado, em suma, contribuir para a constituição do "eu" social, assegurando, desse modo, a sobrevivência da sociedade.

Nessa discussão, torna-se plausível pontuar que nossa educação brasileira foi pautada pelos princípios da educação da pedagogia tradicional: silêncio, autoritarismo, hierarquia, ordem, passividade, omissão, exclusão e falta de igualdade. Desse modo, percebe-se que a escola revela historicamente o seu caráter seletivo nas suas ações educacionais, pois desenvolve desde os primórdios de sua trajetória uma educação que, tanto na forma do sistema de ensino como no atendimento às classes sociais, diferencia o acesso e as condições de permanência dos alunos na escola.

Vale salientar que, na década de 1960, à qual foi marcada por intensos processos de industrialização e urbanização pelo Brasil, a educação escolar aparece como elemento de grande importância estratégica dentro do projeto de modernização da sociedade. E o reflexo desse panorama nacional, agitado pelas promulgações das Leis 4024/61 (BRASIL, 1961), 5540/68 (BRASIL, 1968) e 5692/71 (BRASIL, 1971) todas regulamentando os ensinos fundamental, médio e superior.

Por conseguinte, no final do século XX a educação escolar passou a ser vista pelo governo como o "remédio" perfeito para as mazelas sociais, frente às expectativas de melhorias das condições de vida dos indivíduos e superação das desigualdades sociais. No Brasil, o progressivo interesse de diferentes esferas governamentais sobre a escola, nesse período, se manifestou por meio de instrumentos de planejamento, legislação e projetos no campo da educação.

Dessa forma, mobilizações, a exemplo da Conferência Mundial de Educação para Todos, Jomtien - Tailândia (ONU, 1990); Seminário sobre Qualidade, Eficiência e Equidade na Educação Básica, promovido pelo IPEA 1991 (GOMES; AMARAL SOBRINHO, 1992) e a Conferência Nacional de Educação para Todos (1993), (BRASIL, 
1994), postulam a necessidade de "fortalecer a gestão e ampliar sua autonomia", pela descentralização como estratégia de construção de escolas eficazes, "direção prioritária da política educacional”. (BRASIL, 1993).

Nesse contexto, é notório observar o descumprimento do Estado na garantia do direito á educação de qualidade para todos. Direito este já conquistado desde a Constituição Federal (BRASIL, 1988). O que percebemos são escolas cada vez mais sucateadas, professores com pouca ou quase nenhuma formação e com baixos salários, dentre outros. O que corrobora para a não permanência de crianças e jovens no âmbito escolar.

Este artigo é parte integrante da pesquisa em desenvolvimento que, dentre outras abordagens, discute a obra do sociólogo através do projeto intitulado "Florestan Fernandes, movimentos sociais e educação no Brasil". Neste participo como bolsista de iniciação cientifica (CNPQ) e desenvolvo estudo sobre a temática da educação, destacando as intervenções intelectuais e práticas de Florestan, sobretudo, no período compreendido entre os anos de 1940 a 1995.

O objetivo central deste é desvelar o percurso histórico da educação brasileira, para em seguida, analisar a efetivação do direito à educação compreendendo a dinâmica política em prol de sua garantia. Além de destacar a atuação intelectual e prática de Florestan Fernandes na investida em favor da democratização da educação brasileira, fomentando a reflexão da necessidade de uma educação de qualidade e acessível a todos.

O trabalho foi elaborado a partir da pesquisa bibliográfica e documental, tendo como principais balizadores Souza (2001), Saviani (1996) e Ianni (2004). Ainda, tomamos por referência artigos científicos e revistas que terçam sobre o assunto. Ainda, a Lei de Diretrizes e Bases n 9394/96 (BRASIL, 1996), a Constituição Federal (BRASIL, 1988) e a Declaração Universal dos Direitos Humanos (ONU, 1948).

Sua estrutura se inicia discorrendo sobre o contexto histórico da educação brasileira e o desafio do acesso, frente ao impasse do Estado em sua garantia, em seguida pontua a trajetória inicial da vida e obra de Florestan Fernandes com os impasses e conquistas que acompanharam o autor desde sua infância até a fase adulta. Portanto, são apresentadas as contribuições de Florestan Fernandes na luta por uma educação pública e de qualidade, na qual é perceptível a sua militância e emblemática política em prol da consubstanciação da democratização do ensino público. 


\section{Breve histórico da educação brasileira}

A gênese do sistema educacional brasileiro esteve fundamentada nos ideais de catequização que tinha como objetivo, alfabetizar na língua portuguesa, com intuito de impor a cultura branca, a religião católica, entre outros aspectos aos primeiros habitantes do País. Os pioneiros nesse ensino foram os Jesuítas, especialistas na catequese religiosa e na conversão dos nativos. Estes montaram uma escola dualista, na qual de um lado o povo e do outro os filhos dos colonos.

Dessa forma, como os detentores do saber, na época vigente, eram os jesuítas; embora tivessem sido expulsos em decorrência da Reforma Pombalina em 1759, seu modelo de ensino permaneceu por um século e meio. Nisto, a Reforma Pombalina não criou uma nova estrutura de ensino, permanecendo o mesmo sistema limitado e deficiente até na formação dos mestres, visto que mesmo com a inserção de novos modelos educacionais, no qual a escola era pautada aos interesses do Estado e não mais da Igreja, um exemplo disso era o ensino hermenêutico.

A chegada da Família Real em 1808, não significou a implantação de um sistema de educação no Brasil, já que a educação continuava tendo uma importância secundária. Todavia, permitiu uma nova ruptura com a situação anterior. Analisamos que para a estadia de D. João se abriu Academias Militares, Escolas de Direito e Medicina, a Biblioteca Real, o Jardim Botânico; além da mudança administrativa, a Imprensa Régia. Entende-se que, tanto no período do Império quanto do Republicano, a educação brasileira não "sofreu" mudanças em seus moldes pedagógicos e nem na questão dos subsídios por parte dos governantes. Sobre isso Bello (2001) diz que:

\footnotetext{
Por todo o Império, incluindo D. João VI, D. Pedro I e D. Pedro II, pouco se fez pela educação brasileira e muitos reclamavam de sua qualidade ruim. Com a Proclamação da República tentou-se várias reformas que pudessem dar uma nova guinada, mas se observarmos bem, a educação brasileira não sofreu um processo de evolução que pudesse ser considerado marcante ou significativo em termos de modelo. (BELLO, 2001, p.2).
}

Com a chegada dos anos de 1930, sob os ventos da escola Nova e de Anísio Teixeira. Assim, as mudanças educacionais ocorridas no período acompanharam o desenvolvimento capitalista, sob um discurso de que a educação seria base para a ascensão social. 
Cabe-se citar o Manifesto dos Pioneiros da Educação (1932) (TEIXEIRA, 1984), como ficou conhecido a iniciativa dos reformadores esteve representado por Lourenço Filho. Segundo Almeida et al. (2010) o movimento defendia a educação pública como direito universal laico contrapondo-se a educação elitista. Tinha por intuito democratizar o acesso a escola e modernizar conteúdos e métodos por ela utilizados.

Já no período compreendido entre os anos de 1964-1985, época da Ditadura Militar, juntamente com sua total repressão, violação de direitos, autoridade exacerbada, onde professores e estudantes foram presos; universidades foram invadidas, dentre outros. Houve ainda, a grande expansão das universidades no Brasil e a meta de combater o analfabetismo com a criação do Movimento Brasileiro de Alfabetização - MOBRAL, contrapondo-se ao método Paulo Freire.

Em meio à repressão da ditadura, que é instituída a Lei 5.692, a Lei de Diretrizes e Bases da Educação Nacional, em 1971 (BRASIL, 1971). Esta com a característica de tentar dar a formação educacional um cunho profissionalizante. Com isto, entende-se que a pretensão do governo na investida pelo ensino profissionalizante era o de garantir mão de - obra para a indústria.

Em suma, se percebe que a educação no Brasil, esteve sempre ligada aos fatores econômicos e políticos da cada época e que a pesar de ao longo da história várias tenham sido as reformas no planejamento educacional, a educação permanece com um ensino superficial, ou seja, um ensino que oferece o básico de conhecimento e não favorece a construção crítica do pensamento dos alunos, a fim de prepara-los a suas vidas práticas.

\section{Educação: direito do cidadão e dever do estado}

O direito de todos á educação foi legitimado pela Constituição Federal de 1988 (BRASIL, 1988), na qual o concebeu como um direito social (artigo $6^{\circ}$ da CF/88). Nisto, o Estado passou formalmente a ter a obrigação de garantir educação de qualidade a todos brasileiros.

Para tanto, a Declaração Universal dos Direitos Humanos (1948) estabelece que: Art.26 - "1. Toda pessoa tem direito à instrução. 2. A instrução será orientada no sentido do pleno desenvolvimento da personalidade humana e do fortalecimento do respeito pelos direitos humanos e pelas liberdades fundamentais" e que a educação escolar, no Brasil, é direito de todos e dever do Estado e da família sendo incentivada em regime de colaboração com a sociedade e tendo por objetivo o pleno desenvolvimento da pessoa, 
seu preparo para o exercício da cidadania e sua qualificação para o trabalho (BRASIL, 1988).

Para Gadotti (1992, p.52) “[...] a riqueza social se reflete no desenvolvimento da natureza humana condicionada ao desenvolvimento das forças produtivas". A partir dessa assertiva, entendemos que para que o indivíduo desenvolva suas potencialidades é necessário um ensino de qualidade que contribua, sobretudo, para a formação do sujeito como agente transformador da sua realidade de vida.

Ramos (2009, p.1) entende que o pleno desenvolvimento da pessoa humana “[...] transcende a tarefa da escola, tendo em vista que o desenvolvimento pleno deve ser garantido em todas as dimensões humanas, como, por exemplo, o cognitivo ou intelectual, o físico, o motor, o espiritual, o social, o trabalho, a arte".

Assim, percebemos que para que haja desenvolvimento pleno, tornam-se necessárias condições favoráveis e que este, por ser considerado pleno, deverá ser completo atingindo todas as dimensões humanas.

Nesta conjuntura, o Estado tem o dever de garantir uma educação de qualidade para todos em regime de colaboração com a família, conforme previsto no art. 205 da Constituição Federal de 1988: “[...] a educação, direito de todos e dever do Estado e da família, será promovida e incentivada com a colaboração da sociedade, visando ao pleno desenvolvimento da pessoa, seu preparo para o exercício da cidadania e qualificação para o trabalho". (BRASIL, 1988, p.34).

Deste modo, compreendemos que o Estado juntamente com o apoio da família, na verdade diria que é um regime de corresponsabilidade social, sendo que o primado do dever fica com o Estado, entendido aqui como o Poder Público, representado pelos entes intergovernamentais: União, Estados, Distrito Federal e Municípios. E a família cabe a tarefa de educar os filhos sob tutela, tendo a responsabilidade de matriculá-los, em idade escolar, nas instituições de ensino.

Nesse ínterim, A lei específica da educação, Lei de Diretrizes e Bases da Educação Nacional (n. ${ }^{\circ}$ 9.394/1996) (BRASIL, 1996), estabelece no Art. $4^{\text {o }}$ ser dever do estado garantir:

I - ensino fundamental, obrigatório e gratuito, inclusive para os que a ele não tiveram acesso na idade própria;

II - progressiva extensão da obrigatoriedade e gratuidade ao ensino médio; $[\ldots]$;

V - acesso aos níveis mais elevados do ensino, da pesquisa e da criação artística, segundo a capacidade de cada um; 
VI - oferta de ensino noturno regular, adequado às condições do educando;

VII - oferta de educação escolar regular para jovens e adultos, com características e modalidades adequadas às suas necessidades e disponibilidades, garantindo-se aos que forem trabalhadores as condições de acesso e permanência na escola; [...];

IX - padrões mínimos de qualidade de ensino, definidos como a variedade e quantidade mínimas, por aluno, de insumos indispensáveis ao desenvolvimento do processo de ensino-aprendizagem. (BRASIL, 1996, p.2).

Ademais, podemos dizer que a educação é um direito fundamental e que compete ao Poder Público promover ações não só no fomento de políticas públicas, mas também no empenho de subsídio e fiscalização desse direito. No entanto, a população deve estar ciente de suas responsabilidades e direitos para com a educação, pois desse modo poderá participar mais ativamente das questões que rege o meio educacional, bem como de lutar por melhorias concretas nesse âmbito.

\section{Florestan Fernandes: breve relato de vida ${ }^{3}$}

Florestan Fernandes nasceu em São Paulo, no dia 22 de Julho de 1920. Sua luta pela vida começou já na infância, para conquistar o próprio nome - já que sua madrinha, que era patroa de sua mãe, o chamava de Vicente, por considerar que Florestan Fernandes não era nome de pobre.

Devido ás necessidades de sua família, Florestan Fernandes começou a trabalhar aos seis anos de idade, onde desempenhou vários ofícios como engraxate, auxiliar de marceneiro, auxiliar de barbeiro, alfaiate e balconista de bar. Como sua vida no trabalho estava exigindo que se dedicasse em período integral, aos nove anos de idade parou de estudar no terceiro ano do curso primário. Somente aos dezessete anos conclui o supletivo por insistência dos fregueses do Bar Bidu, na Rua Líbero Badaró, onde trabalhava como garçom, pois achavam que Florestan era muito inteligente devido aos comentários sobre a política e a leitura da realidade que fazia.

Era vendedor de produtos farmacêuticos quando, aos 18 anos, ingressou na Faculdade de Filosofia, Ciências e Letras da Universidade de São Paulo em 1947, formando-se em ciências sociais e obteve o mestrado na Escola de Sociologia e Política em 1947. Doutorou-se em 1951 e foi assistente catedrático, livre docente e professor

${ }^{3}$ WILD, B. Florestan Fernandes. [online]. Disponível em:

<http://meuartigo.brasilescola.com/biografia/florestan-fernandes-1.htm〉. Acesso em: 29 out. 2011. 
titular na cadeira de sociologia, substituindo o sociólogo e professor francês Roger Bastisde em caráter interino até 1964, ano em que se efetivou na cátedra.

O autor começa a escrever no final dos anos 40 e ao longo de sua vida publicou mais de 50 livros e centenas de artigos. Dentre suas principais obras, estão: A organização social dos Tupinambás (1949); A função social da guerra na sociedade Tupinambá (1952); A integração do negro na sociedade de classes (1964); A revolução burguesa no Brasil (1975) e outras.

Florestan Fernandes esteve ligado ao Partido dos Trabalhadores (PT) desde sua fundação. Em 1986 filiou-se ao partido e exerceu dois mandatos de deputado federal (1987-1991 e 1991-1995). Ainda, colaborou com a Folha de São Paulo desde os anos 40 e, em junho de 1989, passou a ter uma coluna semanal nesse jornal.

Cândido (2001), intelectual, amigo de Florestan por mais de 50 anos, descreve a carreira do professor Florestan Fernandes em três momentos com a seguinte citação:

\begin{abstract}
"Houve um Florestan dos anos 40, um Florestan dos anos 50 e um Florestan dos anos 60 a partir do qual a síntese já estava feita". O Florestan dos anos 40 é o da construção do saber, que ao construir o seu, constrói a possibilidade de saber dos outros. O Florestan dos anos 50 é o que começa a se apaixonar pela explicação do saber do mundo, porque, tendo já os instrumentos na mão, se dedica a aplica-los para compreender os problemas do mundo. O terceiro momento é o do Florestan que, tendo aplicado o saber à compreensão do mundo, transforma-o numa arma de combate. Naturalmente, as três etapas estão misturadas, pois sempre houve a terceira na primeira e, a primeira na terceira. "Estou me referindo às predominâncias." (SOUZA, 2001, p.28).
\end{abstract}

No ano de 1995, falece Florestan Fernandes na cidade de São Paulo, aos 75 anos de idade, vítima de embolia gasosa maciça (presença de bolhas de ar no sangue), seis dias após submeter-se a um transplante de fígado. Ele estava revisando os originais de seu último livro: A contestação necessária - retratos intelectuais de inconformistas e revolucionários, uma coletânea de biografias de amigos e heróis.

\title{
O intelectual militante e o professor engajado em favor da educação
}

Florestan Fernandes, esse grande intelectual, a convite de Lula, inicia sua vida política no PT, em 1986 exercendo dois mandatos de Deputado Federal (1987-1990 e 
1991-1994), sendo sempre coerente e valorizando a diversidade dentro do partido, sendo por isso bastante admirado pelos seus colegas partidários. Dessa forma, no parlamento, dedica-se a defender as causas dos menos favorecidos, sem nunca abandonar sua dedicação ao tema educação, desempenhando um papel de grande relevância na Constituinte de (1986-1988), na qual este compreendia que através da Constituição se poderia melhorar as desigualdades presentes no projeto Educacional dos movimentos sociais.

Com toda a sua atuação na Constituinte, Florestan Fernandes começa a tecer críticas sobre o posicionamento do parlamento que dava indícios de autoritarismos e conservadorismo que na concepção de Florestan Fernandes seus discursos eram envoltos de tensões entre passado autoritário e as perspectivas futuras e que a constituição de 1988 foi um processo inacabado.

É pertinente discorrer sobre a atuação do professor Florestan, em busca de melhorias na educação, dando ênfase ás reflexões da realidade brasileira e, sobretudo na militância em prol nos menos favorecidos. Dessa forma, como membro da subcomissão que tratava da educação, sobretudo a pública, na Constituinte incidiu emendas em seu favor tais como: o direito inalienável de todos os brasileiros á educação pública, garantido pelo Estado, com vistas ao desenvolvimento pleno da personalidade humana, á aquisição de aptidões para o trabalho, á formação de uma consciência social crítica e á preparação para a vida.

Ainda destacamos: a obrigatoriedade de creches e pré-escolas para crianças de zero á seis anos de idade; autonomia didático-científica, administrativa e financeira da Universidade, que associa o ensino, pesquisa e extensão e à democratização efetiva da universidade, através da autogestão, do estabelecimento de critérios públicos e transparentes com participação dos docentes, alunos e funcionários, dentre outras.

Segundo Ianni (1986), as contribuições de Florestan para a Sociologia brasileira, tem origem em cinco fontes: na Sociologia clássica e moderna; no pensamento marxista, na corrente mais critica do pensamento brasileiro, sobretudo, dos escritores e cientistas sociais do sec. XIX; nos desafios de sua época, a começar pelos anos 40 e nos grupos e classes sociais que compreendem a maioria do povo.

Na década de 40, por entrar em contato com as obras marxistas com todas as suas discussões sobre o pensamento dialético. Florestan começou a entender os assuntos em torno da dominação da sociedade burguesa e de suas expressões na sociedade atual. Isto, 
também aguçou o pensamento crítico que já existia nele, e a partir de então funda a sociologia crítica no Brasil.

$\mathrm{Na}$ década de 50, Florestan direciona-se á temática do racismo, onde levantou uma série de questionamentos sobre o mito da democracia racial e deu espaço para o estudo da democracia de modo mais abrangente.

\section{Florestan Fernandes - a favor da escola pública e de qualidade}

Nas décadas de 1940 e 1950, vários intelectuais participaram da Campanha em Defesa da Escola Pública, que teve origem nas discussões para a aprovação da primeira LDB. Porém, nenhum foi mais ativo do que Florestan Fernandes, como reforça Saviani $(1996$, p.6) foi a "[...] liderança mais expressiva e combativa do movimento em defesa da escola pública naquele período". Nessa época publicou inúmeros escritos em que tecia criticas sobre as pretensões da escola privada e se posicionava em defesa da democratização do ensino público.

Dessa forma, Florestan entende que a escola é um espaço de construção de conhecimento, não alheio á realidade de vida, mas que aguça debates críticos acerca da realidade de vida dos sujeitos. Bem como, de formação pedagógica e politica, por isso se empenhava em lutar por essa causa tanto no Congresso Nacional, como nas ruas e nas universidades.

Nesse intuito, Florestan como conhecedor das questões em torno da educaçãoproblemáticas de acesso e desafios- tinha a educação como um fator de mudança social. Nisto, empenhou-se na elaboração, defesa e aprovação de emendas favoráveis á educação pública; enquanto membro da subcomissão que tratava da temática na Constituinte.

De fato, não eram somente as condições estruturais do sistema educacional que atraíam a atenção rigorosa do cientista social. Outras questões tais como: a destinação de verbas; a criação de uma maneira de integrar as escolas para que sua função progressista se multiplicasse e ganhasse solidez. Além, dessas condenava a postura dos educadores distante do processo social, acreditando que estes deveriam estar engajados na tarefa de transformação social.

Nesse intuito, Florestan Fernandes permaneceu em sua luta pela democratização do ensino brasileiro, exercendo pressão para preservar os direitos já adquiridos e trabalhando para assegurar a aquisição de outros mais. Como aponta um fragmento de uns dos seus discursos: “[...] Portanto, escola pública, de alta qualidade é um requisito 
fundamental para a existência da democracia [...] Por isso, peço a todos que votem comigo, com PT, com os Partidos democráticos desta Casa: verbas públicas para a escola pública! (Palmas). (FERNANDES, 1989, p.21).

E nessa luta incansável em prol da democratização da educação pública, Florestan Fernandes enfrentou muitos desafios, não sendo possível garantir em lei todas as solicitações da Comissão e do Fórum para o ensino público. No entanto houve avanços significativos, dentre tais: o direito a escola pública e gratuita em todos os níveis foi garantido; garantida a destinação de verbas para a educação. Além das universidades ganharam autonomia didático-científica e administrativa, além da junção entre ensino, pesquisa e extensão. Já no campo da escola pública as vitórias alcançadas ficaram em torno da permanência de algumas conquistas.

Segundo Barros (2011) a participação intensa de Florestan como sociólogo, publicista e deputado constituinte foi, sem dúvida, indispensável na luta por um espaço maior para a educação no conjunto dos objetivos nacionais expressos na atual Constituição Federal.

\section{Conclusão}

Percebemos que a educação é a chave para se alcançar a completa compreensão sobre si, os demais, suas ações e do mundo que o cerca. Dessa forma, a educação deve oportunizar que os indivíduos sejam agentes construtores de sua própria história de vida, permitindo a construção de uma sociedade civilizada, na qual direitos e deveres sejam respeitados e postos em prática.

Entendemos que a educação pública e de qualidade é o caminho para o avanço econômico e social do País; uma vez que uma população escolarizada pode exercer mais plenamente os seus direitos políticos e de cidadania de uma forma geral. Porém, a valorização dessa temática tem sido pouco explorada nas discussões parlamentares do nosso país, dando lugar ao descaso do poder público no subsídio de um direito já conquistado pelo povo e garantido por lei.

Nesse contexto, vale ressaltar o empenho de Florestan Fernandes em favor da democratização do ensino brasileiro, rechaçando o ensino privado e elitizante, exercendo pressão para preservar os direitos já adquiridos e trabalhando para assegurar a aquisição de outros mais. Este foi um elo entre o movimento nacional pela escola pública e todos os que por ele interessavam-se. 


\section{THE IMPORTANCE OF SCHOOL EDUCATION IN FLORESTAN FERNANDES: CHALLENGES AND PROSPECTS DEMOCRATIZATION}

ABSTRACT: Understanding the education as a right for all and which was conquered from the Federal Constitution (1988). Thus, this study aims to unveil the central history of Brazilian education to then analyse the implementation of the right to education including the political dynamic in favor of your warranty. In addition to highlighting the intellectual and practical performance of Florestan Fernandes in the onslaught in favor of the democratization of education. The work was elaborated from bibliographic and documentary research, having as main underpinning Candido (2001) Saviani (1996), Ianni (2004). Furthermore, we take by reference scientific articles and journals that terçam on the subject. In the meantime, we realized that the educational practice, the tireless activism and scientific production of Florestan Fernandes remains as a significant contribution, serving for example booster fights that we are summoned to fight for democracy and the quality of education.

KEYWORDS: Florestan Fernandes. Education. Democratization.

\section{REFERÊNCIAS}

ALMEIDA, A. M. A. et al. Ensino Médio: direito nosso, dever do Estado. Disponível em: <http://educas.com.br/blog/wpcontent/uploads/2010/10/artigo-do-ensinom\%C3\%A9dio11.pdf >. Acesso em: 08 jan. 2014.

BARROS, J. S. M. Florestan Fernandes: práxis e educação transformadora. 2011.70f. Trabalho de Conclusão de Curso (Especialização)-Faculdade de Pedagogia, Universidade Estadual do Ceará, Fortaleza, 2011.

BELLO, J. L. P. Educação no Brasil: a história das rupturas. Pedagogia em Foco, Rio de Janeiro, 2001. Disponível em: <http://www.pedagogiaemfoco.pro.br/heb14.htm>. Acesso em: 02 mai. 2012.

BRASIL. Conferência Nacional de Educação para Todos - Anais. Brasília: MEC/SEF, 1994.

. Constituição (1988). Constituição [da] Republica Federativa do Brasil.

Brasília, DF: Senado Federal, 1988.

Federal, 1971.

Lei de Diretrizes e Bases da Educação Nacional: no 5692/71. Brasília: Senado

. Lei de Diretrizes e Bases da Educação Nacional: nº 5540/68. Brasília: Senado Federal, 1968.

Lei de Diretrizes e Bases da Educação Nacional: no 4024/61. Brasília: Senado Federal, 1961. 
Lei n. 9394/96 de 20 de dezembro de 1996. Lei de Diretrizes e Bases da Educação Nacional. Diário Oficial [da] Republica Federativa do Brasil, Brasília, 20 dez. 1996.

COUTO, A. C. N.; SANTOS, I. R. S. Por que vamos ensinar Música na escola? Reflexões sobre conceitos, funções e valores da educação musical escolar. Opus, Goiânia, v.15, n.1, p.110-125, jun., 2009. Disponível em: 〈http://www.anppom.com.br>. Acesso em: 29 out. 2011.

FERNANDES, F. O desafio educacional. São Paulo: Cortez: Autores Associados, 1989.

FREIRE, P. Pedagogia da autonomia: saberes necessários à prática educativa. 34. ed. São Paulo: Paz e Terra, 1996.

GADOTTI, M. Concepção dialética da educação: um estudo introdutório. 9. ed. São Paulo: Cortez, 1992.

GOMES, C. A.; AMARAL SOBRINHO, J. (Org.). Qualidade, eficiência e equidade na educação básica. Brasília: IPEA, 1992.

IANNI, O. (Org). Florestan Fernandes: sociologia critica e militante. São Paulo: Expressão popular, 2004.

ONU. Assembleia Geral das Nações Unidas. Declaração Universal dos Direitos Humanos. 1948. Disponível em:

<http://portal.mj.gov.br/sedh/ct/legis_intern/ddh_bib_inter_universal.htm>. Acesso em: 29 out. 2011

Declaração Mundial sobre Educação para Todos: satisfação das necessidades básicas de aprendizagem. Jomtien: UNESCO, 1990.

RAMOS, J. Projeto educativo e político-pedagógico da escola de ensino médio: tradições e contradições na gestão e na formação para o trabalho. 2009. 245f. Tese (Doutorado em Educação Brasileira)-Universidade Federal do Ceará, Fortaleza, 2009.

SAVIANI, D. Florestan Fernandes e a educação. Estudos Avançados, São Paulo, v.10, n.26, jan./abr., 1996.

SOUZA, A. C. M. Florestan Fernandes. 1. ed. São Paulo: Editora Fundação Perseu Abramo, 2001.

TEIXEIRA, A. S. O manifesto dos pioneiros da educação nova. Revista Brasileira de Estudos Pedagógicos, Brasília, v.65, n.150, p.407-425, mai./ago., 1984. 